\title{
CARE, UNCARE, AND THE CITY
}

\author{
Angelika Gabauer, Sabine Knierbein, Nir Cohen, Henrik Lebuhn, \\ Kim Trogal, and Tihomir Viderman
}

The making of this volume coincided with COVID-19, which confronted the world with tremendous health, social, economic, and political challenges, thus confirming that the conceptualization of care in urban studies is a task worth pursuing. The more a place was affected by the threat of contagion and its consequences, the more care was perceived as a key ingredient of shared everyday lives. Either the presence or absence of both traditional and more innovative forms of care was felt in daily struggles, and affected urban residents across all their differences. At one end of the spectrum, underequipped hospitals and care homes, sites of flexibilized labor, and companies and businesses exploiting seasonal workers, like agricultural farms and slaughterhouses, appeared to be the rule rather than the exception. The 'care crisis' at such places, and especially in related overcrowded housing with poor sanitation facilities, has revealed multiple dimensions of vulnerability of urban societies. At the other end of the spectrum, however, everyday life practices have flourished during this time, creating dense support networks even at places of previously celebrated anonymity:Young volunteers and delivery workers rushed on their bikes to deliver food or medicines to quarantined residents, neighbors took care of each other using staircase baskets and virtual platforms, care workers and activists worked around the clock to help, and urban dwellers chanted from balconies to mourn the missing social encounters in public spaces.

Amidst the pandemic, societies and public institutions have been compelled to adopt new forms of taking care- from mutual aid to physical distancing and social isolation. In spatial relations, the pandemic has unraveled the urban as a place of particular vulnerability, in which market rule displays a tendency toward undermining the (inter)national decent living standards with the state and its regulative forces being either rather absent or overly present. Scholars with a focus on the role of care in crisis management pointed out that "COVID-19 measures are necessary to save the lives of some of the most vulnerable people within society, and yet in parallel they create a range of negative everyday effects for already marginalized people" (Branicki 2020: 872). Most responses to the pandemic were dominated by national 'one-size-fits-all' policies characterized by the logic of large state bureaucracies rather than by more nuanced and spatially sensitive strategies that would pay attention to the particular needs and risks of specific groups. The consequences of such crisis management involve "elevated 
risk for workers in low-paid, precarious and care-based employment, overrepresentation of minority ethnic groups in case numbers and fatalities, and gendered barriers to work" (ibid.).

The disruptive and uneven features of the pandemic and its prevention measures have deeply impacted the quality of social relations and the ways in which societies treat care. In addition, the care crisis also signals an urban crisis, a crisis of cities as a collective political project. Simultaneously, the unalienated caring relations based on material and spatial moments of mutual encounter offer a way out of the very same crisis. This volume therefore introduces the care debates into the field of urban studies as an analytical prism on the urban crisis, while proposing an urban and spatial focus as a productive means for revisiting and informing research on forms of care, uncare, and the city in the social sciences and humanities, as well as other fields.

\section{Conceptualizing Care and 'Uncare'}

To use care as a conceptual lens and as an empirical focus means to recognize and engage with an important body of scholarly work and activism which has developed since the 1970s. It includes feminist struggles around the recognition of reproductive labor (Federici 1975; Fortunati 1995), the epistemological implications of new standpoints based on care and domestic work (Hartsock 1983; Smith 1974), and conceptualizations of care as a mode of ethical action qualitatively different from discourses on rights and justice (Noddings 1984; Tronto 1993).

In the subsequent two decades, the feminist care tradition has been embraced by a variety of disciplines. From education (Shevalier and McKenzie 2012) and social work (Meagher 2004) to business, economics, and accounting (Hamington and Sander-Staudt 2011), care- or the lack thereof-has been mobilized as a conceptual framework for studying a broad range of phenomena, from migration and citizenship policies to commercial surrogacy (Parks 2010). The feminist care tradition has also been referred to as a hopeful anchor point in rethinking the relation between architecture and capitalism in favor of practices that would in an ethical and inclusive way engage with the deteriorating ecological conditions, while acknowledging various forms of labor and creating conditions for the co-existence of different economies (Fitz and Krasny 2019). Scholars have furthermore been committed to "diagnosing the nature of the care crisis, showing in detail how and why social carelessness has come to structure and take hold of so many dimensions of life" (Chatzidakis et al. 2020: 6). Thereby they have articulated the care of others, society, and the environment as a valid alternative to the destructive force of (urban) financialized capitalism (Fraser 2016).

Beyond hopeful conceptualization of new architectural practices and urban projects as manifestations of care, this book sets out to explore the spatiality of care regimes, and the ways in which care work and care relations with their inherent ambivalences play out under different urban conditions. Care is thereby discussed in regard to two aspects: as an urban tension field between care and uncare, and as a new discourse about care and the urban. The former offers an analytical lens to better understand why care is gaining academic attention in urban studies, through the focus on the ways uncaring relations have been unfolding in recent years and through certain patterns of urbanization. The latter illustrates how care debates have vigorously permeated the realms of urban development from very different directions, i.e., planning theory, political science, human geography, medical studies, and urban and particularly labor sociology, community economy, from social work and cultural studies approaches. 
This plethora of entry perspectives into an urban(ized) understanding of care also represents a diversity that emerges from the situatedness and specificity of different caring relations and practices. In this vein, no clear-cut definition of care in urban studies has emerged. However, the new debates can and do build on a number of strong concepts and established lines of research, such as crisis-theories (and their careful contestation), conceptualizations concerning uneven geographies of care, as well as the possibility of moments of meaningful encounters in public spaces that provide experiences of unalienated caring relations. It is in these moments that care can help alter the quality of social relations toward realizing and respecting 'others.'

\section{Understanding Care Between Entrepreneurial Scripts and Mutual Praxis}

Various forms of urban precarity and vulnerability can be grasped as a social manifestation of the tension field between uncare and care. It comes to the fore in the lived spaces of contemporary cities through, for instance, expressed social struggles and structural antagonisms. Embracing the tension between care and uncare as a research perspective also allows for acknowledging multiple and overlapping vulnerabilities and the intersectional nature of different axes of discrimination. We approach uncaring conditions and the lack of care in urban development not as 'naturally' given facts, but rather as being produced over time in relation to the restructuring of the welfare state, the dismantling of state provisions, and particularly within an increasingly entrepreneurial script for the future (Ong 2011) based on individual self-governance and 'care of the self' (Dilts 2011). However, bounding care to the entrepreneurial, self-responsible, adaptive, indeed neoliberal subject "derives from the refusal to recognise our shared vulnerabilities and interconnectedness, creating a callous and uncaring climate for everyone, but particularly for those dependent on welfare, routinely accused of preferring 'worklessness and dependency"' (Chatzidakis et al. 2020: 13, original emphasis). Individualized considerations about independent self-care run the risk of being co-opted by urban policy makers. Such forms of "carewashing" rather follow an entrepreneurial tonality while adding an agenda of corporate social responsibility (ibid.: 11; see also Chapter 2, this volume). In contrast, highlighting aspects of collective and mutual social interaction in care discourse can help to disentangle care debates from an entrepreneurial and individualistic, rational-choice based script for the urban future.

On a conceptual level, care refers to at least three different but interrelated meanings (Ruddick 1998: 4): Firstly, care is understood as a kind of labor, hence, it is linked with (feminist) struggles for recognition of domestic labor and social reproduction. Secondly, care as a particular relationship puts focus on the relational reciprocity, thus illuminates that the work of care "is constituted in and through the relation of those who give and receive care" (ibid.: 14). Thirdly, care is associated with an ethical practice that has its roots in moral philosophy, and which presupposes vulnerability, interdependent agency, and mutual responsibility as fundamental features of social relations. This means that care encapsulates what people do (spatial praxis) when they care, how they mutually interact (social relations) when caring, and how and why they tend to reflect on these doings and interactions in a morally informed way (care ethics).

Emphasizing dependency and vulnerability as constitutive elements of human life, however, also produces tensions within care's conceptual vocabulary. Many of these concepts "still bear negative connotations and reproduce dominant ideas, theoretical categories and 
subjectivities that continue to devalue care" (Atkinson et al.2011:568). Discourses that aim to valorize (inter)dependency simultaneously find some difficulty in addressing critiques raised by disability rights activists, where the struggle for independent living sharply highlights that dependency is not intrinsically valuable or desirable per se. Rather, dependency and independency should not be seen as "antithetic" (Puig de la Bellacasa 2017: 4). By critically interrogating dominant mobilizations of vulnerability as fragility and weakness, vulnerability can rather be conceived of beyond its interpretation as needing care due to individual failure toward enabling an openness and receptiveness to alternative imaginings of the embodied self, relations, and places in ways that can enhance capacities. Analyzing debates of care and uncare this way speaks to the importance of understanding people not just as multifaceted individuals but also as active parts of a web of social relations and spatial practices of reciprocity.

The focus on care as interdependence also involves an understanding of social relations not simply from a rational-choice perspective or based on individualistic ways of mastering one's own life. It rather rests on the idea of the relational dependence between humans, other beings, and the environment, all of which have spatial dimensions. This relational space is first and foremost shaped by 'being-in-common,' which implies a view of the world in which human beings are considered as always enmeshed in social relations with others (Chapter 3, this volume).

\section{Locating Care in the City}

Understanding care in a world of being-in-common thus refers to a certain idea of the urban as being constitutive of the emergence of mutual relations, and therefore enhances the focus on urban space as produced through (caring or uncaring) spatial practices and social relations. Decades of the retreat of the welfare state have changed facets of uncaring practices in urban development. It is especially on the urban scale where the lack of institutional care manifests as a structural and systemic neglect mediated through conflicts and antagonisms in everyday life. The care crisis therefore needs to be seen as being closely entangled with the urban crisis. In that respect Andreas Chatzidakis, Jamie Hakim, Jo Littler, Catherine Rottenberg, and Lynne Segal (2020:4) have emphasized that "neoliberalism [...] has neither an effective practice of, nor a vocabulary for care," it is "uncaring by design" (ibid.: 10). And one could add: It is constantly enhancing the degree of social crisis related to its lack of effective practice of care, thus reproducing and aggravating the urban crisis.

Translations of the concepts of care in the field of urban studies have delivered critically important strides toward more nuanced spatial understandings of care with the focus on challenges that individuals, social groups, and institutions face as they seek to employ care practices (Atkinson et al. 2011). By tackling socio-political implications of care at different spatial and social, infrastructural, and institutional levels that intermingle with urban everyday life, urban studies have linked the endeavors of ethical engagement with urban inhabitants, communities, and collectives to the matters of spatial justice, urban rights, and 'the right to the city' (Purcell 2013).

However, despite the efforts of some notable scholarship (see Kathiravelu and Bunnell 2018; Lancione 2014; Rusenko 2018), contemporary urban studies scholarship remains rather more dominated by conceptual frameworks of rights and justice (Fainstein 2010; Harvey 2012; Marcuse et al. 2009). Yet even though, as Miriam Williams (2017: 821) aptly points out, the restriction of care to the private sphere and justice to the public sphere has been indeed 
critiqued and re-framed, "care has predominantly remained absent from debates about justice in the city. Urban theory has largely missed the call to recognize care as a transformative ethic that can guide our thinking on what constitutes the just city."

Inspired by a feminist body of thought, it is in this light that we see a new generation of urban theorization emerging where care and justice are not seen as opposing rationales: Karen Till (2012: 8), for instance, explicitly links the concept of the just city with ethics of care perspectives, claiming that "a place-based ethics of care offers possibilities to create and plan for more socially just cities." Similarly, Williams (2017) introduces the idea of 'care-full justice' that conceptually brings together feminist ethics of care approaches with predominant discourses on rights and justice in cities. Post-colonial perspectives extend the debate in urban studies beyond the domain of rights arguing that urban conflicts may well be understood against the backdrop of institutional care, or lack thereof. Thus, the manufactured deprivation of formalized care frameworks by urban regimes-in housing, education, health, or infrastructure-not only exacerbates the care deficit in ever-diversifying cities and pushes rival social groups to engage in a race to the bottom over scarce resources, but further forces them to engage in defensive urban citizenship (Cohen 2015), and offer little-if any care for their fellow urban residents (Cohen and Margalit 2015).

\section{Writing about Cities and Care: Structure and Scope of the Book}

In order to engage with care not only as an analytical scope for understanding the urbanizing world, but also as a potential for altering social conditions, a deeper link between space, society, and care needs to be carved out. This book represents such an endeavor and offers an array of contributions that deal with different manifestations and understandings of urban care in various geographical contexts. Against processes of capitalist urbanization manifesting extractive, perverted, and dispossessive features, daily struggles continue to reshape interpersonal geographies of inequality toward more just and egalitarian futures, with a promise of a more egalitarian society. Taking these ambivalences impinging everyday lives of urban dwellers as a starting point, authors throughout the book explore different dimensions of care on the following aspects: They have started to register different forms of the lack of care in relation to social inequality by working on spatial aspects of precarity, marginalization, and the production of disadvantage (Chapters 6, 9, and 20, this volume); they have invested an effort to study urban regimes of care by pointing to aspects of capitalist and colonial patterns of urbanization and how they embed different caring relations (Chapters 5 and 11, this volume); they have provided an argument to connect debates on care, labor, and society and have spanned the social focus of care between the spaces of individualization, solidarization, and (de)collectivization (Chapters 3, 6, 13, 15, and 18, this volume); they have explored the ordinary features of care by analyzing lived space and involving forms of critique of everyday life (Chapters 8 , 9,15 , and 17, this volume); they have assembled knowledge on geographies of encounter and public space by stressing affective and performative dimensions of care (Chapters 7, 8, $9,13,14,17$, and 20 , this volume); they have emphasized the need to frame care ecologies while further developing controversies around urban and rural scales and efforts of scaling care (Chapters 6, 19, and 21, this volume); they have addressed care from a transnational and translocal perspective involving topics of migration, mobility, and post-migration (Chapters 5 , 11 , and 20, this volume), and they have maneuvered through a range of ambivalences of care and uncare by distinguishing nuances between careful, careless, and carefree cities and by 
highlighting different attitudes of caring and uncaring city authorities (Chapters 2, 12, and 18 , this volume).

The broad spectrum of contributions of this volume identifies and analyzes these various and interweaving urban geographies of care and uncare. Authors coming from variegated knowledge fields, including anthropology, architecture, history, human geography, planning, political science, sociology, urban design, and urban studies examine how care practices impact upon and transform urban space. The contributions of the book surface both the political ambivalences inherent to care regarding social progress achieved so far and ongoing struggles around care, as well as reflect on the power of caring practices in shaping civic innovation and solidary urban futures. The volume pursues a systematic integration of a plurality of empirical, methodological, theoretical, and ethical approaches to care in urban studies. In this way, it situates the care debate in closer relation to empirical analysis and theoretical advances when studying the city, urbanization, and urban space. With this, the anthology contributes to the growing body of literature that comprises conceptual endeavors linking different care debates for a more systematic use in urban studies.

The book is divided into four sections:

Part I Conceptualizing Care: Encounters, Critique, and Commons is of an introductory nature and outlines the overall conceptual framework of the book. It explores the tension between fields of care and uncare and inherent ambivalences to situate the book within broader theoretical debates on cities, urbanization, and urban life. This section ties the three subsequent focal areas into one overall intersectional approach in urban studies that makes use of the study of care.

Part II Social Inequalities, Uneven Space, and Care introduces approaches for an understanding of care that enhances the study of social inequality and the uneven production of space. The section brings together contributions with a particular focus on forms of inequality, their spatial manifestations, and efforts toward ethical engagements and meaningful social relations.

Part III Everyday Struggles and Contestations Around Care explores struggles emerging around provisions of care and the lack of caring infrastructures in the city. It particularly deals with care labor as an essential element for sustaining urban societies and brings together research on the range of struggles and contestations taking place around (un)waged care.

Part IV New Care Arrangements and Civic Innovation discusses different endeavors and formations that emerge in response to precarious conditions of care, which are often quite ambivalent themselves and torn between being integrated into forms of neoliberalization and/or collective resistance. With this, approaches are introduced that aim at re-framing care from the margins.

\section{Revisiting Care in Urban Studies}

In praxis-based urban theory and theoretically informed urban praxis we need an ethical, empirical, methodological, and theoretical understanding of how processes of socially producing care and uncare, and the spatial constellations influencing these processes or resulting from them, have come into place. And we need critical explorations of how they play out in processes of urbanization across the individual-collective divide. This book, since it emerges from the field of urban studies, contributes such a spatial perspective and understanding of care by exploring three aspects in particular: 1) How the scale of analysis and research in urban theory contributes to wider understandings of the changing landscape of care; 2) how moments of 
presence and encounters in public space allow detection of care labor in everyday urban life and possibilities for its alteration; and 3) how care and crisis are fundamentally linked.

\section{Exploring Care: Scales, Spaces, Politics}

This book promotes a place-sensitive exploration of urban geographies of care as situated and context-specific, and simultaneously moves beyond this place-boundedness to include reflections on moral geographies. Focusing on the situated and context-specific features of care demands an understanding of the spatial implications of the politics of scale. This implies integrating an analysis of the micro-scale and that an ethically 'proximate' or 'distant' approach does not necessarily coincide with spatial proximity or distance. Ilona Ostner (2011: 469f) identified an analytical shift away from micro-analyses of care that focus on the particular care relations between care provider and receiver, the asymmetries in these relationships, and the feelings involved, toward macro-analyses - such as for example a political economy of care work. Yet macro-analyses are seen to have some risks in that they can foreground insensible approaches to care and move away from a moral and 'soulful' understanding of care as a concept toward a sober analytical perspective (May 2014). While macro-perspectives thus offer on the one hand a more distanced view, on the other hand, due to their inherent abstraction, they take a less critical stance regarding social and interpersonal ambiguities of care (ibid.). Hence, instead "of the dominant positioning of care as pre-political and private within social policy and society," we follow an argument from feminist theories "which renders political the relational aspects of bodies and care" (Atkinson et al. 2011:567).

Micro-research of lived space allows exploration of the quality of different types of caring and uncaring encounters between strangers in the city, while meso-research helps to link such an analysis to policy making and institutional (social) infrastructures influencing the wider local framing conditions of such encounters. Macro-research of lived space can help to unbound situated research and re-address wider geopolitical, translocal, and transnational aspects of caring and uncaring regimes and of care economies, and how they mediate local social encounters, while at the same time being contested and altered through mutual ways of 'becoming-related' through face-to-face contact in local spaces. It is in critical everyday life research in urban studies that we can combine a multisectional, multiscalar, and transversal analysis of lived caring experiences, and lived spaces devoid of or filled with meaningful caring practices.

\section{Caring Encounters: Moments of Presence and Geographies of Encounter}

Our interest in these spaces and places of care involves the exploration of the spatial and urban features of different types of encounters and how they flow in the now, in which deeply caring and affective relations may eventually unfold. The roles of both the body and of social encounters are key features through which to understand the changing geographies of care as spaces of emergence and 'becoming-related.' Here we follow research on care that invites us to distinguish between non-commodified and alienated versions of care. Such research articulates alienated versions of care, in which the caregiver offers a rational and reason-based service to a care receiver which is based on contract and distance, in contrast to non-commodified care, in which mutually caring subjects both give and receive in a form of mutual relatedness and unalienated moments of truly caring for others. While the first form 
is associated with the self-instrumentalization of care workers and the de-subjectivization of care receivers (who become mere care objects in the alienated forms of providing care as a paid service), the latter may become constituted when this type of alienation is overcome in moments of human encounter (May 2014: 43).

The quality of care is embedded in the quality of social relations between people involved in caring. Such 'moments of presence' [in German: Gegenwartsmomente] are those types of social encounters in which affective contact shapes existential forms of meeting others while mutually realizing and respecting others in their human subjectivity beyond existing hierarchies and institutions (ibid.: 33, referring to Stern et al. 2012). It is in these moments that the intersubjective field of those involved needs to be "dramatically reorganized," because their habitual framing of the familiar intersubjective environment changes or is at stake to radically change (ibid., own translation). This moment holds the opportunity for the subjects involved to alter their own relational way of 'becoming-related' with one another. Thus, a new quality of 'moments of encounter' can start to thrive in which a subject is able to alter its own position and learn (ibid.). Here, care and caring practices are not treated as a standardized plannable procedure with clearly stated and commodifiable goals, but need to be conceptualized as situations of encounter in mutual exchange (May 2014:32) as part of the human condition. In that sense the mutual co-production of human subjectivity might allow the alienation enforced by a careless regime to be overcome (at least for a moment), through pure mutual recognition as humans with their own subjectivity (ibid.: 40). Analyzing the 'geographies of encounters' to address the tension field between care and uncare, therefore, overcomes a mere domination-resistance binary toward a focus on the altering potential of moments of encounter and their everyday geographies (Valentine 2008).

\section{Dramatizing Care: Beyond Crisis Response?}

In this volume we have also been concerned with how care debates are born from crisis debates, and inform these debates. We consider this a key issue that needs to be reflected upon for any dealing with care in urban studies. This is particularly relevant if care is used as a moral principle to catalyze emancipatory, liberating, and inventive thought to reverse the aforementioned devastating and unsettling tendencies of capitalist urbanization and its continuous modus operandi: crisis.

Angelika Fitz and Elke Krasny (2019) situate care as a life-saving praxis capable of meeting the climate crisis while acknowledging capitalism's and human's roles in producing, leveraging, or preventing the crisis. While the global climate crisis concerns us all, environmental devastation still impacts us very differently. Critical scholars and activists have been pointing out that the governmental strategies to 'manage' climate change will reinforce lines of discrimination, marginalization, and informalization of groups and urban communities around the world already suffering multiple forms of crisis and their impacts. The focus on care in this context allows for considerations of work, labor, and environment, and to address timely pressure to act in view of a 'broken planet' (ibid.). This work has been directed more specifically to the professions dealing with the built environment, and promotes practices of 'healing,' 'repair,' and 'revival' (ibid.). It refers to care as a 'species activity', which implies a philosophical position relating to the way people care for one another (Fisher and Tronto 1990). Such approaches also shed light on the need to analyze care's intersection with practices of power. Other positions "beginning from an explicit focus on care of the body (rather than 
environment, non-human species or markets)" also offer valuable "entry points for furthering a critical geography of care" (Atkinson et al. 2011: 568), while other perspectives, such as María Puig de la Bellacasa's (2017), follow feminist traditions to locate the politics of care as privileging those voices and perspectives otherwise marginalized.

In that sense, it is important to reflect upon the relation between framing crisis and framing care. "The paradoxical hypothesis"-as Henri Lefebvre (2014: 713, original emphasis) put it - "is that this 'crisis' cannot be reduced to a phase of instability between two stable periods: Quite the reverse, it is becoming the mode of existence of modern societies on a world scale." Instead, continuous crisis is the everyday state of things, it affects the social as the "anthropological matrix, their historical foundation" (ibid.: 714). In this respect, is framing care contingent on the features of crisis we envisage to address, or can an ethics of care also help to develop counter concepts to overcoming an overly crisis-centered and partly dystopian view of urban futures?

\section{Materializing Care: Toward an Understanding of (Un)Care and the City}

By posing this question we wish to better grasp the ambivalences involved in the social production of uneven geographies of care, and how and to what extent care may become a byproduct or an alteration of crisis and opportunity. The ordinary tension between care and uncare in urban development can be sensed when looking concretely at spatially manifested caring practices, such as those present in self-organized initiatives which meet urgent needs yet simultaneously manifest forms of neoliberal governmentality and individual (self)responsibilization. Registering care in urban studies, therefore, needs to be connected to a continued analysis of different modes of crisis, particularly of the uneven geographies of caring encounters in urban public space and beyond. However, to grasp the different crisis moments and how they may feed into an intersectional understanding of the urban crisis as 'multiple crises' (Brand 2016) requires research perspectives that help connect different axes of uncare, discrimination, and neglect. Hence, we engage with practices of further developing intersectional research approaches around care inequalities and simultaneously embrace care's conceptual altering potential for more egalitarian urban presents.

This book has been driven by a particular interest for the spatiality and urban character of caring or uncaring (social) relations, that is, by an endeavor to identify and understand the caring or uncaring experiential spaces of urban societies, and the role spaces play in (re)producing care inequalities, or in acknowledging and overcoming these. Doreen Massey's (2005) calling for a more politically responsible spatial theory urged urban scholars to take difference more seriously and extend care relations beyond the local. Her reiteration of the inequalities within which our everyday socio-spatial lives are embedded was followed by an equally strong plea to engage in a careful manner with distant and unfamiliar 'others,' both at home and beyond. In this respect, we need to ask how care debates embrace (or not) earlier debates on redistribution, and to what extent they move beyond or behind them. Christine Milligan and Janine Wiles (2010) conceptualized 'landscapes of care' as the social, spatial, and emotional ensembles which underpin care work and relations that encompass the institutional, domestic, familial, communal, public, voluntary, and private social infrastructures of care. Hence, they are "spatial manifestations of the interplay between the socio-structural 
processes and structures that shape experiences and practices of care" (ibid.: 739). This implies that "any attempt to understand care means that we need to consider [...] all those involved in the care relationship" and highlights the relevance of the spatial dimension, insofar as "the nature, extent, and form of these relationships are affected by "where they take place"' (ibid.: 738 , original emphasis).

By conceiving of care both as relational and simultaneously as materialized, this book explores the mutually formative relations between materiality and social relations in conflictive and creative processes of urbanization. We situate care inequalities, antagonisms, and ambivalences at the heart of any productive and ethical engagement with urban transformations. With the aim of scrutinizing practices and relationships of care as constitutive of any urban phenomenon interlinked with a social world of being-in-common, this collection illustrates the inherent spatiality of caring: Care sits in places, flows through spatial networks, extends across territorial borders, and maps itself onto the ethnicized, racialized, classed, gendered, and sexual divisions of contemporary cities (see Atkinson et al. 2011). At the intersections of city and space, this perspective contributes to a deep understanding of what is distinctly 'urban' in caring practices and how a perspective of care can enable just, productive, and ethical engagement with urban transformations.

Placing care in its full moral and political context means to "not focus exclusively on the morality of individual action or on socio-political structures and systems," rather, to investigate "both together, placing action in structural context and considering structural contexts in terms of actions that are supported or held back" (Hugman 2018: 121). Uncare structurally hits those groups and individuals within the wider society, which already experience precariousness, exploitation, and an exposed risk of being negatively affected. Uncare thus can be considered an institutional, spatial, and systemic multiplicator of bodily vulnerability and social inequality. Care does not necessarily lead toward more equal living conditions in cities. It can only contribute to this endeavor if coupled to spatial practices of material and symbolic redistribution, and if fostered by affective geographies of care in which moments of presence are turned into moments of encounter.

The book engages with the analytical dimensions of care by emphasizing everyday life as a dazzling, yet ambivalent interface for intersectional research on multiple aspects of care. Such an approach, we suggest, might paint a fuller picture of the complexities of everyday urban life, and has the potential to provide insight into the aforementioned urban antagonisms and ambivalences which territorially manifest in emerging conflicts around space and resources in different cities around the world. The collection of research in this book sheds light on how the uneven social production of everyday spaces in contemporary processes of urbanization has produced frameworks that lack care. And it offers articulations, which state a new normative demand for (re)establishing careful institutions and relations, or by pointing to already existing caring practices and the empirical evidence about social relations characterized by innovative forms of solidarity, mutual understanding, and friendship as essential ingredients of human subjectivity.

Openly caring attitudes between people, if combined with soulful moments of encounter in public space, can provide the glue that holds together urban societies even in difficult times of unsettling and increasing structural antagonisms signaling an urban crisis. Deeply caring about others, in this regard, requires realization and respect of others in their human subjectivity, an exercise which can be best trained in openly and accessible spaces that provide room for caring with, caring for, and caring about one another. 


\section{References}

Atkinson, S., Lawson, V. and Wiles, J. (2011) Care of the Body: Spaces of Practice. Social and Cultural Geography 12(6): 563-572.

Brand, U. (2016) How to Get Out of the Multiple Crisis? Towards a Critical Theory of SocialEcological Transformation. Environmental Values 25(5): 503-525.

Branicki, L.J. (2020) COVID-19, Ethics of Care and Feminist Crisis Management. Gender, Work and Organization 27(5): 872-883.

Chatzidakis, A., Hakim, J., Littler, J., Rottenberg, C. and Segal, L. (2020) The Care Manifesto: Politics of Interdependence. London: Verso.

Cohen, N. (2015) Southern (Dis)Comfort: Defensive Urban Citizenship in Tel Aviv. In T. Matejskova and M. Antonsich (eds.) Governing Through Diversity: Migration Societies in the Post-Multiculturalist Age. London: Palgrave Macmillan, pp. 161-180.

Cohen, N. and Margalit, T. (2015) 'There Are Really Two Cities Here': Fragmented Urban Citizenship in Tel Aviv. International Journal of Urban and Regional Research 39(4): 666-686.

Dilts, A. (2011) From 'Entrepreneur of the Self' to 'Care of the Self': Neo-Liberal Governmentality and Foucault's Ethics. Foucault Studies 12(October): 130-146.

Fainstein, S. (2010) The Just City. Ithaca: Cornell University Press.

Federici, S. (1975) Wages Against Housework. Bristol: Power of Women Collective and Falling Wall Press.

Fisher, B. and Tronto, J.C. (1990) Toward a Feminist Theory of Caring. In E.K. Abel and M.K. Nelson (eds.) Circles of Care: Work and Identity in Women's Lives. Albany: State University of New York Press, pp. 35-62.

Fitz, A. and Krasny, E. (2019) Introduction: Critical Care. Architecture and Urbanism for a Broken Planet. In A. Fitz, E. Krasny and Architekturzentrum Wien (eds.) Critical Care: Architecture and Urbanism for a Broken Planet. Cambridge, MA: MIT Press, pp. 10-22.

Fortunati, L. (1995) The Arcane of Reproduction: Housework, Prostitution, Labor and Capital. New York: Autonomedia.

Fraser, N. (2016) Capitalism's Crisis of Care. Dissent 63(4): 30-37.

Hamington, M. and Sander-Staudt, M. (eds.) (2011) Applying Care Ethics to Business. Heidelberg: Springer Science and Business Media.

Hartsock, N.C.M. (1983) The Feminist Standpoint: Developing the Ground for a Specifically Feminist Historical Materialism. In S. Harding and M.B. Hintikka (eds.) Discovering Reality. Dordrecht: Springer, pp. 283-310.

Harvey, D. (2012) Rebel Cities: From the Right to the City to the Urban Revolution. London: Verso.

Hugman, R. (2018) Humanitarian Aid and Social Development: A Political Ethics of Care View of International Social Work Practice. In B. Pease, A. Vreugdenhil and S. Stanford (eds.) Critical Ethics of Care in Social Work: Transforming the Politics and Practices of Caring. New York: Routledge, pp. 116-126.

Kathiravelu, L. and Bunnell, T. (2018) Introduction: Urban Friendship Networks: Affective Negotiations and Potentialities of Care. Urban Studies 55(3): 491-504.

Lancione, M. (2014) Entanglements of Faith: Discourses, Practices of Care and Homeless People in Italian Cities of Saints. Urban Studies 51(14): 3062-3078.

Lefebvre, H. (2014) Critique of Everyday Life: The One-Volume Edition. London: Verso.

Marcuse, P., Connolly, J., Novy, J., Olivo, I., Potter, C. and Steil, J. (eds.) (2009) Searching for the Just City: Debates in Urban Theory and Practice. New York: Routledge.

Massey, D. (2005) For Space. London: Sage Publications.

May, M. (2014) Auf dem Weg zu einem dialektisch-materialistischen Care-Begriff. Widersprüche 34(134): 11-51.

Meagher, G. (2004) Modernising Social Work and the Ethics of Care. Social Work and Society 2(1): $10-27$.

Milligan, C. and Wiles, J. (2010) Landscapes of Care. Progress in Human Geography 34(6): 736-754. 
Noddings, N. (1984) Caring: A Feminine Approach to Ethics and Moral Education. Berkeley: University of California Press.

Ong, A. (2011) Introduction: Worlding Cities, or the Art of Being Global. In A. Roy and A. Ong (eds.) Worlding Cities: Asian Experiments and the Art of Being Global. Oxford: Blackwell, pp. 1-26.

Ostner, I. (2011) Care-eine Schlüsselkategorie sozialwissenschaftlicher Forschung? In A. Evers, R.G. Heinze and T. Olk (eds.) Handbuch Soziale Dienste. Wiesbaden: VS Verlag für Sozialwissenschaften, pp. 461-481.

Parks, J.A. (2010) Care Ethics and the Global Practice of Commercial Surrogacy. Bioethics 24(7): 333-340.

Puig de la Bellacasa, M. (2017) Matters of Care: Speculative Ethics in More than Human Worlds. Minneapolis: University of Minnesota Press.

Purcell, M. (2013) Possible Worlds: Henri Lefebvre and the Right to the City. Journal of Urban Affairs 36(1): 141-54.

Ruddick, S. (1998) Care as Labor and Relationship. In J.G. Haber and M.S. Halfon (eds.) Norms and Values: Essays on the Work of Virginia Held. Lanham: Rowman and Littlefield, pp. 3-25.

Rusenko, R. (2018) Imperatives of Care and Control in the Regulation of Homelessness in Kuala Lumpur, Malaysia: 1880s to Present. Urban Studies 55(10): 2123-2141.

Shevalier, R. and McKenzie, B. (2012) Culturally Responsive Teaching as an Ethics- and Care-Based Approach to Urban Education. Urban Education 47(6): 1086-1105.

Smith, D.E. (1974) Women's Perspective as a Radical Critique of Sociology. Sociological Inquiry 44(1): $7-13$.

Stern, D.N., Bruschweiler-Stern, N., Lyons-Ruth, K., Morgan, A.C., Nahum, J.P. and Sander, L.W. (2012) Veränderungsprozesse: Ein integratives Paradigma. Frankfurt am Main: Brandes und Apsel.

Till, K.E. (2012) Wounded Cities: Memory-Work and a Place-Based Ethics of Care. Political Geography 31(1): 3-14.

Tronto, J.C. (1993) Moral Boundaries: A Political Argument for an Ethic of Care. New York: Routledge.

Valentine, G. (2008) Living with Difference: Reflections on Geographies of Encounter. Progress in Human Geography 32(3): 323-337.

Williams, M.J. (2017) Care-Full Justice in the City. Antipode 49(3): 821-839. 